\title{
Benthien, Claudia, Martus, Steffen, Die Kunst der Aufrichtigkeit im 17. Jahrhundert
}

\section{Philippe Büttgen}

\section{OpenEdition}

\section{Journals}

Édition électronique

URL : http://journals.openedition.org/ifha/1670

DOI : $10.4000 /$ ifha. 1670

ISSN : 2198-8943

\section{Éditeur}

IFRA - Institut franco-allemand (sciences historiques et sociales)

Référence électronique

Philippe Büttgen, «Benthien, Claudia, Martus, Steffen, Die Kunst der Aufrichtigkeit im 17. Jahrhundert », Revue de l'IFHA [En ligne], Date de recension, mis en ligne le 01 janvier 2008, consulté le 22 septembre 2020. URL : http://journals.openedition.org/ifha/1670 ; DOI : https://doi.org/10.4000/ifha.1670

Ce document a été généré automatiquement le 22 septembre 2020.

(CIFHA 


\title{
Benthien, Claudia, Martus, Steffen, Die Kunst der Aufrichtigkeit im 17. Jahrhundert
}

\author{
Philippe Büttgen
}

L'idée de ce volume a quelque chose d'extrêmement neuf. Une certaine anthropologie historique, en partie relayée par des travaux d'histoire intellectuelle sur la doctrine des passions à l'âge classique, s'est émerveillée de ce que les hommes de jadis n'aient pas ri ou pleuré des mêmes choses que " nous ", qu'ils aient été bouleversés par ce qui nous charme à peine (un arc-en-ciel) et relativement peu atteints - croit-on savoir - par ce qui nous révolte (un enfant mort). Le fait est que nous avons peu d'accès aussi immédiat à l'étrangeté du passé que par l'affect et les passions ; peu de choses nous font autant mesurer la distance de ce qui n'est plus que les émotions que nous ressentons ou croyons ressentir au plus près de nous-mêmes, et que nos prédécesseurs ne connaissaient pas. On aurait là un des théorèmes de l'anthropologie historique : l'appel à notre nature sensible, supposément immuable, est en fait révélateur d'histoire. Mais n'avons-nous pas, en la matière, pris un peu l'habitude de déjouer nos propres attentes ? Sommes-nous encore réellement surpris par l'énoncé qui dit : « Nous avons cru que le rire, les larmes, le rosissement, les cris, le silence, la colère et l'amour étaient uniformes et immuables, il n'en est rien » ? Et que pouvons-nous encore construire à partir de cela ? À bien des égards, l'anthropologie historique est victime de son succès; ce qu'elle dit convainc toujours, mais se renouvelle peu.

C'est la raison pour laquelle cet Art de la sincérité au XVIIe siècle, produit d'un travail collectif réunissant majoritairement des germanistes, pourra paraître important aux historiens - la collection Frühe Neuzeit de Niemeyer satisfaisant par là une fois de plus parfaitement à son cahier des charges. Avec la notion d'Aufrichtigkeit, ce n'est plus en effet une passion ou un affect qui est exploré, mais une disposition de parole et de comportement, à la fois permanente et diffuse : à côté de la " sincérité », on y entend aussi la « droiture » (le richtig de l'aufrichtig), une certaine ouverture et prestance de probité, celle qui incite, sinon à " dire tout ce qu'[on] pense ", du moins à " parler toujours comme [on] pense ", comme la définit le dictionnaire d'Adelung cité dans la 
substantielle préface des éditeurs. Les essais rassemblés dans le volume s'attachent à tout ce que ce naturel à la fois postulé et visé dans le verbe et dans le geste comporte d'« art » et de technique : technique rhétorique, la véracité de l'orateur entrant dans la définition de son ethos pour assurer l'efficacité du discours ou sa "vivacité » (D. Niefanger, W. Barner), technique sociale (par exemple dans le cas extrême de l'honnêteté du " Parfait Ambassadeur » d'Ancien Régime, avec sa gestion du secret étudiée par H. Kugeler), l'une et l'autre mobilisant une sémiotique corporelle dont l'étude renvoie, en les renouvelant, à des domaines déjà partiellement circonscrits par l'anthropologie historique (le corps féminin et le maquillage chez M. Czarnecka, la danse et la question d'une " sincérité du corps » chez M.-Th. Mourey). Par plusieurs biais, le volume fait sentir l'importance que revêt la question de la sincérité dans les caractéristiques nationales en cours d'élaboration à l'époque moderne, à commencer par le motif de la "Aufrichtigkeit und alte Teutsche Treu », qui fait de l'Allemagne le pays vérace opposé à la dissimulation française (belle étude d'I. Stöckmann sur la " communauté des sincères » et la probité comme fondement du social au XVIIe s.). Les deux contributions les plus inventives par l'ampleur de leur documentation et la nouveauté de leurs objets touchent à des matières partiellement religieuses : J. A. Steiger éclaire les dimensions d'une théologie de la rectitude chez Luther et dans la première orthodoxie (ou, comme il l'appelle également, le « luthéranisme baroque ») et L. Danneberg, dans la ligne la plus créative de la Begriffsgeschichte, se met à l'écoute des résonances confessionnelles du discours sur la simulatio et la dissimulatio pour finalement parvenir à une refondation non-théologique de l'interdit du mensonge chez Grotius et chez Kant. Dans ce vaste parcours qui passe en particulier par Gracián, cet article et plusieurs autres remettent efficacement en perspective les recherches menées sur la " prudence " et l'émergence de la politique moderne dans la civilité courtisane.

Certes la plupart des contributions du volume restent guidées avant tout par le souci de réhabiliter la littérature et la pensée du baroque contre des Lumières abusivement conçues, selon les éditeurs, comme âge de la sincérité. On ne sera pas non plus obligé de penser qu'il y a un immense paradoxe dans le fait que la sincérité soit, au sens littéral, « artificielle ", ou qu'il y ait une "rhétorique de la sincérité " (p. 7), à moins d'avoir d'abord un peu trop misé moralement : en germanistique, cultural studies ou dans toute autre discipline, dire de son objet qu'il est « construit » signifie tout simplement qu'on veut en faire l'histoire. La plupart des contributions accèdent à la question de la sincérité à partir des catégories de périodisation de l'histoire littéraire, dans lesquelles on pourra se sentir par moments à l'étroit, même quand elles sont contestées. Mais peu importent les intentions : il faut saluer l'objet, sa découverte et sa première mise en œuvre historiographique. Avec l'Aufrichtigkeit, les contributions de ce volume accèdent par un chemin inédit à l'historicité des pratiques de vérité : c'est non seulement le parler-vrai, mais aussi l'être-vrai - réalité, valeur et injonction (be yourself !) - qui en reçoit des lumières nouvelles. L'anthropologie historique, si elle en tient compte, va peut-être passer un cap.

Philippe Büttgen (Centre National de la Recherche Scientifique) 